\title{
The Dominant Cause of Cultural Shock and its Effect on the Students who are Studying at Universitas Katolik De La Salle Manado-Indonesia
}

\author{
Dr. Jozef Raco* (jraco@unikadelasalle.ac.id) \\ Dr. Stevanus Ngenget (sngenget@unikadelasalle.ac.id ) \\ Mr. Yulius Raton (yraton@unikadelasalle.ac.id) \\ Mr. Ronald Rachmadi (rrachmadi@unikadelasalle.ac.id) \\ Universitas Katolik De La Salle Manado, Indonesia \\ Kombos 1 Manado 95253 Indonesia \\ *Corresponding Author
}

\begin{abstract}
People entering a new environment could experience a cultural shock. It can also happen to students who study at a place where the culture is different from their home culture as they may feel unsettled and anxious. Previous studies uncovered the sources of cultural shock, such as being a different culture, having different expectations, facing different customs, speaking a different dialect. Kalvero Oberg (1960) mentioned six negative feelings caused by culture shock, which were: (1) strain resulting from the effort of psychological adaption; (2) a sense of loss or deprivation referring to the removal of former friends, status, role, and possessions; (3) rejection by or rejection of the new culture; (4) confusion in the role definition, role expectations, feelings, and self-identity; (5) unexpected anxiety, disgust, or indignation regarding cultural differences between the old and new ways; and (6) feelings of helplessness as a result of not coping well in the new environment.

Other adverse effects of a cultural shock were discouragement, lethargy, depression, suspicion, boredom, homesickness, anger, extreme sensitivity, irritability, loneliness and loss of familiarity. For students studying in a different cultural setting, this cultural shock may have a negative impact on them.

This research aims to reveal the dominant cause of cultural shock and its effect on the students who are studying at Universitas Katolik De La Salle Manado-Indonesia.

This study used the Analytical Hierarchy Process for data gathering and analysis. The respondents were students of Universitas Katolik De La Salle Manado who came from different provinces of the country. This study benefited the management of the University to improve the program that handled this cultural shock being experienced by the students to enhance their studies at the University.
\end{abstract}

Keywords: cultural shock, management, analytical hierarchy process, students, university

Biographical Notes: Jozef Richard Raco is a lecturer in Business Management at the Universitas Katolik De La Salle Manado. He received his Ph.D in Educational Management from the State University of Jakarta-Indonesia in 2010. He earned his Master of Science in Business Management from the University of East Anglia UK in 2002, Master's in Economics from the Asian Social Institute of Manila-Philippines and Bachelor's in Philosophy from the 
Most Sacred Heart of Jesus Major Seminary of Pineleng, Manado Indonesia in 1990. His research interests are entrepreneurship, spirituality and values in Management.

Dr. Stevanus Ngenget is an Assistant Professor at Universitas Katolik De La Salle Manado. He earned his doctoral degree in 2018 majoring in Linguistics. His writing interet includes pragmatics, implicatures, ICT in teaching and learning and Dynamic Assessment.

Yulius Raton is a lecturer in modeling and simulation of the Industrial Engineering Department at the Universitas Katolik De La Salle Manado Indonesia. He earned his Master's in

Computer science from School of Information Technology Benarif, Indonesia in 2008.

Ronald Rachmadi is a lecturer in Mechanics of Materials of the Industrial Engineering Department at the Universitas Katolik De La Salle Manado Indonesia. He earned his Master's in Mining Engineering from the Bandung Institute of Technology Indonesia in 2007.

\section{Introduction}

Some studies reveal that students who study in other cities or abroad encounter other beliefs, values, and attitudes that are different from theirs. At the time they face those different beliefs, unfamiliar values, and attitudes they can experience confusion. They have to manage themselves to adapt to their new environments. Otherwise, they might have a cultural shock. They usually experience it during their first year of studies when they need to move from their own culture to another culture that brings about psychological stress, depression, anxiety and helplessness (Shieh, 2014). This psychological condition has to be handled as soon as arrive at their study destination otherwise their studies may be jeopardized. The cultural shock affects the new student's study performance since they have to adjust to the environment which is different from their hometown. New students take time to be more familiar with the new culture.

Understanding the cultural shock is essential for the new students, the school administration, and the students' sponsors. The school has to come up with programs or policies such as home training for new students to tell them about the customs, values, and habits of the city or a country they are going to study to minimize the students' problems related to the new culture and environment.

This study aims to reveal the dominant factors of cultural shock as perceived by new students from Papua, Palopo (South Sulawesi) and Poso (Central Sulawesi). Another objective of the study is to find out whether or not the respondents have felt a different perceived-impact. 


\section{Literature Review}

The cultural shock was introduced firstly in 1958 to describe the chaotic emotions of a person living in a new environment (Shieh, 2014) that experiences maladjustment that encompassed psychology, emotions, interpersonal relationships. Those who were in cultural shock condition felt a pressure to adapt to their current environmental demands such as school, work, and society in general. Oberg, an anthropologist, mentioned in 1960 that the cultural shock was a symptom and the process of adapting to a new and different culture (Naeem, et al. 2015). Oberg wrote that people who worked or studied in other cultural settings encountered some external problems. Some of them were different language, different mode of communication, different values and customs which caused a number of reactions such as confusion, anxiety, frustration, irritation, resentment, loneliness, homesickness, unhappiness, self-pity, anger, hostility, estrangement, indecision, physical illness, exhilaration, isolation, inappropriate social behavior and depression. This experience was unpleasant and shocked them. Their expectation did not match to the reality at hand. In this situation, they generated a feeling of helplessness (Rajasekar \& Renand. 2013). They did need time to adjust to the unfamiliar environment.

Some elements of the cultural shock used in the analysis were: strain that was to say the effort needed to make the necessary psychological adaptations; a sense of loss and feelings of deprivation in regard to friends, status, profession and possession; being rejected by the surrounding people from the new culture; confusion in role as expected by the environment, values, feelings and self identity; surprise, anxiety, even disgust and indignation after becoming aware of culture differences; and a feeling of impotence in being able to cope with the new environment.

\section{Methodology}

The researchers used the Analytical Hierarchy Process (AHP) both for data gathering and analysis. This method, which was introduced by Th. Saaty in the 1970s was considered very appropriate by the researchers particularly in making a decision based on the multi-complex variables or factors. This method accommodated qualitative data to be turned into quantitative one. This method was a combination of qualitative and quantitative techniques. There were various reasons for the researchers to use this method. Firstly the findings could be objective because it used numbers rather than words as data. Secondly, it was a well-proven method used 
by many researchers and applied in many disciplines. Many researchers used this method because it assisted them in understanding the context of the problems and made it easy for them to structure the problems to be solved (Banuelas \& Anthony, 2004). Thirdly, the mathematical formula and the calculation were relatively easy. Fourthly there was a software application such as expert choice application to assist researchers in doing the calculation. So it was workable for any research problem. Fifthly, the complicated criteria and sub-criteria could be arranged and simplified in a hierarchical form which was useful for doing the analysis. Sixthly this method used a consistent validation tool where researchers could eliminate redundant data and check its consistency. Seventhly this method was helpful for decision makers in the evaluating procedure (Sinuany-Stern et al., 2006). This method was suitable for this study to uncover the dominant cause of cultural shocks which were experienced by new students who were studying in a different cultural setting.

The Analytical Hierarchy Process began with a hierarchical design consisting of the goal at the top, followed by the criteria and the alternatives. The hierarchical structure of the AHP helped the researchers to simplify the complex problems and broke them down to a simple form. Then we proceeded to establish a pair-wise comparison matrix; the calculation of the priority vector; the calculation of the maximum eigenvalue and finally the examination of the consistency.

Data collection was done through a questionnaire which was designed in AHP format. The questionnaire was then filled out by three groups of new students representing three different

provinces in the country and who experienced a cultural shock in the first year of their studies in Manado. The researchers chose respondents who were new students from outside Manado and who had problems with their studies due to the different values and culture they were encountering. Indeed having direct or personal were main criteria in selecting respondents (Raco \& Tanod, 2014). All the students wanted to participate in this study, and they allowed the researchers to publish the data.

\section{Research Findings}

Oberg in 1960 (Naeem, et al. 2015) mentioned that the elements of cultural shock are :

- Strain resulting from the effort of psychological adaption

- Sense of loss and feelings of deprivation

- Being rejected

- Confusion 
- Surprise

- Feeling of impotence

The alternative elements which are used in the study are the students from the provinces of Papua, Palopo in South Sulawesi and Poso of Central Sulawesi. They are selected because, based on our preliminary study, they are the one who have highly impact on the cultural shock when they study at Manado (North Sulawesi). There are students of 20 provinces studying at Manado. They come to Manado (Fig 1) to study at Universitas Katolik De La Salle (De La Salle Catholic University).

Figure 1. Map of Manado Indonesia

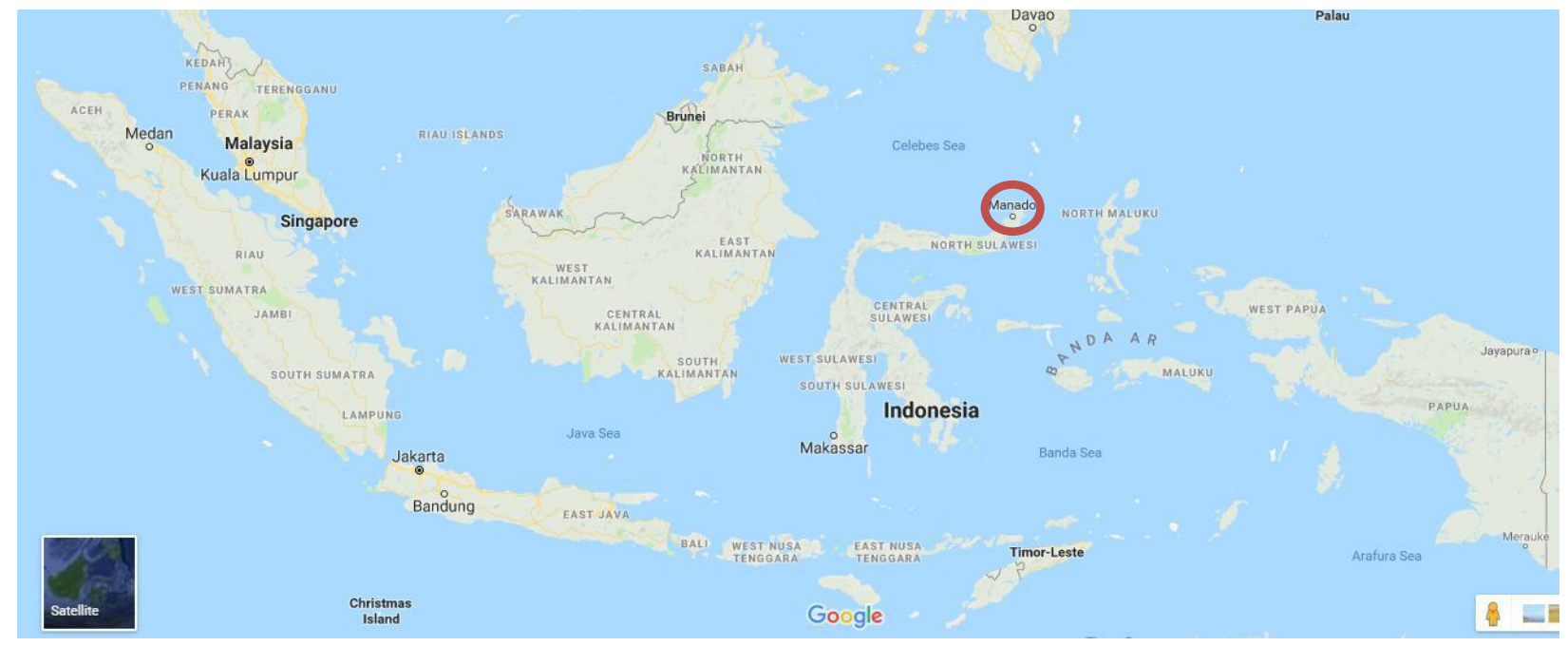

(Source: Google map)

The criteria and the alternatives of the study are constructed in hierarchical form as shown in Fig. 2 . 
Figure 2. The hierarchical structure of the study

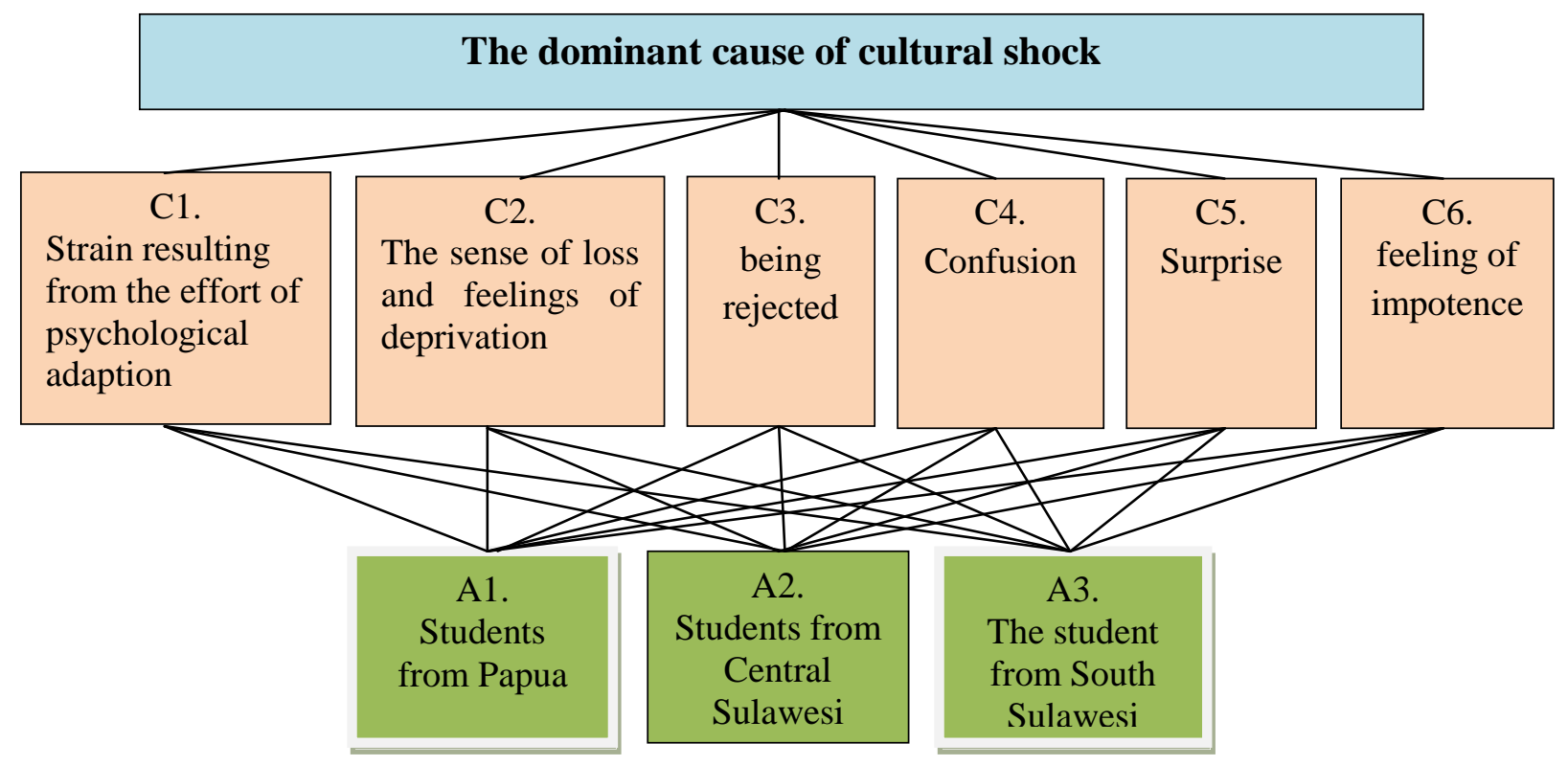

The researchers distributed 50 questionnaires and 35 of them were returned and filled up. The questionnaires were organized in AHP technique as suggested by Th. Saaty. Table 1 is the sample of a questionnaire which was distributed to the respondents.

Table 1. The sample of a questionnaire

\begin{tabular}{|c|c|c|c|c|c|c|c|c|c|c|c|c|c|c|c|c|c|c|}
\hline \multirow[t]{3}{*}{ Criteria } & \multicolumn{17}{|c|}{ Criteria Weighting Score } & \multirow[t]{3}{*}{ Criteria } \\
\hline & \multicolumn{8}{|c|}{ More importance than } & Equal & \multicolumn{8}{|c|}{ Less importance than } & \\
\hline & 9 & 8 & 7 & 6 & 5 & 4 & 3 & 2 & 1 & 2 & 3 & 4 & 5 & 6 & 7 & 8 & 9 & \\
\hline C1 & 9 & 8 & 7 & 6 & 5 & 4 & 3 & 2 & (1) & 2 & 3 & 4 & 5 & 6 & 7 & 8 & 9 & $\mathrm{C} 2$ \\
\hline C1 & 9 & 8 & 7 & 6 & 5 & 4 & (3) & 2 & 1 & 2 & 3 & 4 & 5 & 6 & 7 & 8 & 9 & $\mathrm{C} 3$ \\
\hline $\mathrm{C} 1$ & 9 & 8 & 7 & 6 & 5 & 4 & 3 & 2 & 1 & 2 & (3) & 4 & 5 & 6 & 7 & 8 & 9 & $\mathrm{C} 4$ \\
\hline C1 & 9 & 8 & 7 & 6 & 5 & 4 & 3 & 2 & 1 & 2 & 3 & (4) & 5 & 6 & 7 & 8 & 9 & $\mathrm{C} 5$ \\
\hline C1 & 9 & 8 & 7 & 6 & 5 & 4 & 3 & 2 & (1) & 2 & 3 & 4 & 5 & 6 & 7 & 8 & 9 & C6 \\
\hline $\mathrm{C} 2$ & 9 & 8 & 7 & 6 & 5 & 4 & 3 & 2 & (1) & 2 & 3 & 4 & 5 & 6 & 7 & 8 & 9 & C3 \\
\hline $\mathrm{C} 2$ & 9 & 8 & 7 & 6 & 5 & 4 & 3 & 2 & 1 & 2 & (3) & 4 & 5 & 6 & 7 & 8 & 9 & $\mathrm{C} 4$ \\
\hline $\mathrm{C} 2$ & 9 & 8 & 7 & 6 & 5 & 4 & 3 & 2 & 1 & 2 & (3) & 4 & 5 & 6 & 7 & 8 & 9 & C5 \\
\hline $\mathrm{C} 2$ & 9 & 8 & 7 & 6 & 5 & 4 & 3 & 2 & 1 & (2) & 3 & 4 & 5 & 6 & 7 & 8 & 9 & C6 \\
\hline $\mathrm{C} 3$ & 9 & 8 & 7 & 6 & 5 & 4 & 3 & 2 & 1 & (2) & 3 & 4 & 5 & 6 & 7 & 8 & 9 & $\mathrm{C} 4$ \\
\hline C3 & 9 & 8 & 7 & 6 & 5 & 4 & 3 & 2 & 1 & (2) & 3 & 4 & 5 & 6 & 7 & 8 & 9 & $\mathrm{C} 5$ \\
\hline C3 & 9 & 8 & 7 & 6 & 5 & 4 & 3 & 2 & 1 & (2) & 3 & 4 & 5 & 6 & 7 & 8 & 9 & C6 \\
\hline C4 & 9 & 8 & 7 & 6 & 5 & 4 & 3 & 2 & 1 & (2) & 3 & 4 & 5 & 6 & 7 & 8 & 9 & $\mathrm{C} 5$ \\
\hline $\mathrm{C} 4$ & 9 & 8 & 7 & 6 & 5 & 4 & (3) & 2 & 1 & 2 & 3 & 4 & 5 & 6 & 7 & 8 & 9 & C6 \\
\hline $\mathrm{C} 5$ & 9 & 8 & 7 & 6 & 5 & 4 & 3 & (2) & 1 & 2 & 3 & 4 & 5 & 6 & 7 & 8 & 9 & C6 \\
\hline
\end{tabular}

The respondents filled up the questionnaires using the Saaty's scale of 1 to 9 as appeared in Table 2 below. 
Table 2. Saaty's 9 points of the scale

\begin{tabular}{|c|c|}
\hline $\begin{array}{c}\text { The intensity of relative } \\
\text { importance }\end{array}$ & Definition \\
\hline 1 & Equal Importance \\
\hline 3 & Moderate importance of one over another \\
\hline 5 & Essential or strong importance \\
\hline 7 & Demonstrated importance \\
\hline 9 & Absolute importance \\
\hline $2,4,6,8$ & $\begin{array}{l}\text { Intermediate values between the two neighboring } \\
\text { scales }\end{array}$ \\
\hline
\end{tabular}

All respondents were purposely selected by the researchers since they had to meet some criteria such as having lived-experience, information-rich and wanted to actively participate in the study (Raco \& Tanod, 2014). They allowed the researchers to use the data for publication.

Once the filling-up questionnaires were finished, the researchers then made a pair-wise comparison in a matrix form and calculated them using the formula below (1) and (2) below

$$
\begin{gathered}
A=\left(a_{i j}\right)_{n \times n} \\
=\left(w_{i} / w_{j}\right)_{n x n}=\left[\begin{array}{cccc}
w_{1} / w_{1} & w_{1} / w_{2} & \ldots & w_{1} / w_{n} \\
w_{2} / w_{1} & w_{2} / w_{2} & \ldots & w_{2} / w_{n} \\
\vdots & \vdots & \vdots & \vdots \\
w_{n} / w_{1} & w_{n} / w_{2} & \ldots & w_{n} / w_{n}
\end{array}\right] \\
\text { with }: a_{i j}=\frac{1}{a_{j i}}, \text { for } i \neq j, \text { and } a_{i i}=1, \text { all } i
\end{gathered}
$$

The result of the pair-wise comparison of the criteria is shown in Table 3, 4 and 5 below. 
Table 3. The pair-wise comparison matrix of the criteria according to students from Papua

\begin{tabular}{|c|c|c|c|c|c|c|}
\hline & $\mathrm{C} 1$ & $\mathrm{C} 2$ & $\mathrm{C} 3$ & $\mathrm{C} 4$ & $\mathrm{C} 5$ & C6 \\
\hline $\mathrm{C} 1$ & 1.0000 & 1.1447 & 1.8171 & 1.3662 & 1.0627 & 0.5848 \\
\hline $\mathrm{C} 2$ & 0.8736 & 1.0000 & 0.6934 & 1.2599 & 0.5848 & 1.2599 \\
\hline $\mathrm{C} 3$ & 0.5503 & 1.4422 & 1.0000 & 1.0914 & 0.7937 & 0.7937 \\
\hline C4 & 0.7320 & 0.7937 & 0.9163 & 1.0000 & 2.2894 & 2.0033 \\
\hline C5 & 0.9410 & 1.7100 & 1.2599 & 0.4368 & 1.0000 & 2.1689 \\
\hline C6 & 1.7100 & 0.7937 & 1.2599 & 0.4992 & 0.4611 & 1.0000 \\
\hline
\end{tabular}

Table 4. The pair-wise comparison matrix of the criteria according to students from Poso of the Central Sulawesi

\begin{tabular}{|c|c|c|c|c|c|c|}
\hline & C1 & C2 & C3 & C4 & C5 & C6 \\
\hline C1 & 1.0000 & 1.0924 & 3.0238 & 0.3223 & 0.2373 & 1.0144 \\
\hline C2 & 0.9154 & 1.0000 & 1.4251 & 0.3234 & 0.3233 & 0.4604 \\
\hline C3 & 0.3307 & 0.7017 & 1.0000 & 0.4242 & 0.4127 & 0.4297 \\
\hline C4 & 3.1027 & 3.0922 & 2.3571 & 1.0000 & 0.4297 & 3.0242 \\
\hline C5 & 4.2132 & 3.0934 & 2.4231 & 2.3271 & 1.0000 & 2.2521 \\
\hline C6 & 0.9858 & 2.1721 & 2.3274 & 0.3307 & 0.4440 & 1.0000 \\
\hline
\end{tabular}

Table 5. The pair-wise comparison matrix of the criteria according to students from Palopo of the South Sulawesi

\begin{tabular}{|c|c|c|c|c|c|c|}
\hline & $\mathrm{C} 1$ & $\mathrm{C} 2$ & $\mathrm{C} 3$ & $\mathrm{C} 4$ & $\mathrm{C} 5$ & C6 \\
\hline $\mathrm{C} 1$ & 1.0000 & 1.0203 & 2.0015 & 0.5002 & 0.3252 & 2.0561 \\
\hline $\mathrm{C} 2$ & 0.9801 & 1.0000 & 1.0372 & 0.3406 & 0.3025 & 2.3421 \\
\hline $\mathrm{C} 3$ & 0.4996 & 0.9641 & 1.0000 & 0.5196 & 0.3419 & 1.0034 \\
\hline $\mathrm{C} 4$ & 1.9991 & 2.9363 & 1.9246 & 1.0000 & 0.3792 & 2.0232 \\
\hline C5 & 3.0749 & 3.3063 & 2.9248 & 2.6371 & 1.0000 & 3.0329 \\
\hline C6 & 0.4864 & 0.4270 & 0.9966 & 0.4943 & 0.3297 & 1.0000 \\
\hline
\end{tabular}

The next step is normalizing the pair-wise comparison matrix that is to set those values to become 1 by using the formula (3) and (4) and generate priority vector by using formula (5) below : 
a. Sum each column in the pairwise comparison matrix

$$
a_{i j}=\sum_{i=1}^{n} a_{i j}
$$

b. Create normalize pairwise matrix .

$$
X_{i, j}=\frac{a_{i j}}{\sum_{i=1}^{n} a_{i j}}
$$

c. Create priority vector by dividing the sum of the normalized column matrix by the number of criteria/subcriteria/alternatives.

$$
W_{i, j}=\frac{\sum_{j=1}^{n} X_{i j}}{n}
$$

The results of the normalizing pair-wise for the criteria and priority vector appears the table 6,7 and 8 below.

Table 6. Normalized PCM and Priority Vector of the criteria concerning the goal according to the students from Papua

\begin{tabular}{|c|c|c|c|c|c|c|c|}
\hline & C1 & C2 & C3 & C4 & C5 & C6 & $\begin{array}{c}\text { Priority } \\
\text { Vector }\end{array}$ \\
\hline C1 & 0.1722 & 0.1663 & 0.2616 & 0.2417 & 0.1716 & 0.0749 & 0.1814 \\
\hline C2 & 0.1504 & 0.1453 & 0.0998 & 0.2229 & 0.0945 & 0.1613 & 0.1457 \\
\hline C3 & 0.0948 & 0.2095 & 0.1440 & 0.1930 & 0.1282 & 0.1016 & 0.1452 \\
\hline C4 & 0.1261 & 0.1153 & 0.1319 & 0.1769 & 0.3698 & 0.2565 & $\mathbf{0 . 1 9 6 1}$ \\
\hline C5 & 0.1621 & 0.2484 & 0.1814 & 0.0773 & 0.1615 & 0.2777 & 0.1847 \\
\hline C6 & 0.2945 & 0.1153 & 0.1814 & 0.0883 & 0.0745 & 0.1280 & 0.1470 \\
\hline
\end{tabular}

Table 7. Normalized PCM and Priority Vector of the criteria with respect to the goal according to the students from Poso of the Central Sulawesi

\begin{tabular}{|c|c|c|c|c|c|c|c|}
\hline & C1 & C2 & C3 & C4 & C5 & C6 & $\begin{array}{c}\text { Priority } \\
\text { Vector }\end{array}$ \\
\hline C1 & 0.0948 & 0.0980 & 0.2408 & 0.0682 & 0.0834 & 0.1240 & 0.1182 \\
\hline C2 & 0.0868 & 0.0897 & 0.1135 & 0.0684 & 0.1135 & 0.0563 & 0.0880 \\
\hline C3 & 0.0314 & 0.0629 & 0.0796 & 0.0897 & 0.1450 & 0.0525 & 0.0769 \\
\hline C4 & 0.2942 & 0.2773 & 0.1877 & 0.2115 & 0.1509 & 0.3697 & 0.2485 \\
\hline C5 & 0.3994 & 0.2774 & 0.1930 & 0.4922 & 0.3512 & 0.2753 & $\mathbf{0 . 3 3 1 4}$ \\
\hline C6 & 0.0935 & 0.1948 & 0.1854 & 0.0699 & 0.1560 & 0.1222 & 0.1370 \\
\hline
\end{tabular}


Table 8. Normalized PCM and Priority Vector of the criteria with respect to the goal according to the students from Palopo of the South Sulawesi

\begin{tabular}{|c|r|r|r|r|r|r|c|}
\hline & C1 & \multicolumn{1}{c|}{ C2 } & C3 & \multicolumn{1}{c|}{ C4 } & C5 & C6 & $\begin{array}{c}\text { Priority } \\
\text { Vector }\end{array}$ \\
\hline C1 & 0.124377 & 0.10569 & 0.202482 & 0.091087 & 0.121416 & 0.179451 & 0.137417 \\
\hline C2 & 0.121897 & 0.103583 & 0.10493 & 0.062013 & 0.112919 & 0.204413 & 0.118292 \\
\hline C3 & 0.062143 & 0.099868 & 0.101167 & 0.094614 & 0.127647 & 0.087576 & 0.095502 \\
\hline C4 & 0.24864 & 0.304154 & 0.194702 & 0.18209 & 0.141573 & 0.176579 & 0.207956 \\
\hline C5 & 0.382451 & 0.342479 & 0.295897 & 0.480195 & 0.373346 & 0.264704 & $\mathbf{0 . 3 5 6 5 1 2}$ \\
\hline C6 & 0.060492 & 0.044226 & 0.100822 & 0.090001 & 0.123099 & 0.087277 & 0.08432 \\
\hline
\end{tabular}

The calculations come out with the result that the student from Papua felt confusion with the highest number of $19 \%$ (table 6) when they first come to Manado to study at Universitas Katolik De La Salle Manado. Then followed by the feeling of surprise (18\%). The students of Papua felt confused when they first encounter with the culture, customs, and values of Manadonese which are different with theirs. The feeling of surprise is $18 \%$ which means that their expectations do not coincide with the reality. While the students from Polopo of the South Sulawesi has 35\% (table 8) feeling of surprise and shock. They surprise because what they expect do not match with the reality. They felt surprised about the way of thinking and acting of Manadonese which do not similar with their values, cultures, and customs. The students from Poso of Central Sulawesi has $33 \%$ feeling of surprise (table 7). The data shows that the students from Papua have a different feeling of cultural shock compare to students from Palopo of the South Sulawesi and Poso of the Central Sulawesi, when they first come and study in Manado. For the Papuan feeling of confusion is the highest, while those from Palopo or Poso, the feeling of surprise is the highest.

Saaty introduced the random consistency index (RI) to get the appropriate consistency index.

Table 9 shows the random index value.

Table 9. The random index value

\begin{tabular}{|c|c|c|c|c|c|c|c|c|c|c|c|c|c|c|c|}
\hline $\mathrm{N}$ & 1 & 2 & 3 & 4 & 5 & 6 & 7 & 8 & 9 & 10 & 11 & 12 & 13 & 14 & 15 \\
\hline R.I & 0.00 & 0.00 & 0.58 & 0.90 & 1.12 & 1.24 & 1.32 & 1.41 & 1.45 & 1.49 & 1.51 & 1.48 & 1.56 & 1.57 & 1.59 \\
\hline
\end{tabular}

Through the data gathering process, it happened that the researchers could find some inconsistencies from the respondents in answering the questionnaire. To solve this problem, Saaty introduces a good way to answer that is through the consistency ratio calculation. The 
consistency ratio is comparing the consistency index $(\mathrm{CI})$ of the matrix in question (the one with our judgments) versus the consistency index of a random-like matrix (RI). In AHP, the consistency ratio is explained using the formula (6) below

$$
\begin{aligned}
& C R=\frac{C I}{R I} \\
& \text { Where } C I=\frac{\lambda_{\max }-n}{(n-1)}
\end{aligned}
$$

The Principal eigen value ( $\lambda \max )$ obtained as follows :

- Multiply each element of the priority vector with the sum of each column that corresponding to the pairwise matrix.

- Principal eigen value obtained by summing the result in the first step above.

Saaty (2012) has shown that a consistency ratio (CR) of 0.10 or less is acceptable to continue the AHP analysis. If the consistency ratio is greater than 0.10 , it is necessary to revise the judgments to locate the cause of the inconsistency and correct it.

Based on the calculation using the formula (6) and (7) the researchers got the result of the consistency ratio of the criteria as shown in table 10, 11 and 12 below

Table10. Consistency Index for the criteria concerning the goal according to the students from Papua

\begin{tabular}{|l|c|c|c|c|}
\hline CRITERIA & Priority Vector & $\lambda \max$ & CI & CR \\
\hline C1 & 0.1814 & & & \\
C2 & 0.1457 & \multirow{2}{*}{6.4648} & 0.0930 & 0.0750 \\
\hline C3 & 0.1452 & & & \\
\cline { 1 - 2 } C5 5 & $\mathbf{0 . 1 9 6 1}$ & & & \\
\hline C6 & 0.1847 & & & \\
\hline
\end{tabular}


Table 11. Consistency Index for the criteria with respect to the goal according to the students from Central Sulawesi

\begin{tabular}{|l|c|c|c|c|}
\hline CRITERIA & Priority Vector & $\lambda \max$ & CI & CR \\
\hline C1 & 0.1182 & & & \\
\cline { 1 - 2 } C2 & 0.0880 & \multirow{2}{*}{6.4324} & 0.0865 & 0.0697 \\
\hline C3 & 0.0769 & & & \\
\hline C4 & 0.2485 & & & \\
\hline C5 & $\mathbf{0 . 3 3 1 4}$ & & & \\
\hline C6 & 0.1370 & & & \\
\hline
\end{tabular}

Table 12. Consistency Index for the criteria with respect to the goal according to the students from South Sulawesi

\begin{tabular}{|l|c|c|c|c|}
\hline CRITERIA & Priority Vector & $\lambda \max$ & CI & CR \\
\hline C1 & 0.1374 & & & \\
\cline { 1 - 2 } C2 & 0.1183 & \multirow{2}{*}{6.253932} & \multirow{2}{*}{0.050786} & 0.040957 \\
\hline C3 & 0.0955 & & & \\
\hline C4 4 & $\mathbf{0 . 2 0 8 0}$ & & & \\
\hline C5 & 0.3565 & & & \\
\hline C6 & 0.0843 & & & \\
\hline
\end{tabular}

The calculation of the consistency ratio shows that the result is $<0.1$ or less than $10 \%$. It means that there is consistency throughout the criteria. The result of the findings is valid and acceptable.

\section{Conclusion}

The study concludes that the cultural shock is experienced by the students from other provinces who are studying at Manado even though the degree and the elements of shock are different. This study reveals that the students of Papua and those from Palopo of the South Sulawesi and Poso of the Central Sulawesi have experienced a different element of cultural shock. For the Papuan, the highest percentage (19\%) goes to the confusion while those from Palopo (35\%) and Poso $(33 \%)$ has the same element of cultural shock which is surprising. The school program to handle this problem will be different from one province to the others. Further research is expected to be done to go deeper on why the confusion is the highest for the Papuan and surprise is the highest for students from Palopo and Poso 


\section{References}

Banuelas, R., Anthony, J. (2004). Modified Analytical Hierarchy Process to incorporate uncertainty and managerial aspects. Int. J. Prod. Res, Vol. 42, No. 18, pp. 3851-3872

Batagarawa, R., William, J., Potts, J., Brown.J. (2015). Use of Analytical Hierarchy Process (AHP) as an instrument to develop a solid waste management assessment tool. Global Journal of Advanced Engineering Technology, Vol 4, Issue 2, pp 70-75

Ishizaka, A \& Labib, A. (2009). Analytic Hierarchy Process and Expert Choice: Benefits and Limitations, ORInsight, 22(4), p. 201-220

James Rajasekar, J., Renand, F. (2013). Culture Shock in a Global World: Factors Affecting Culture Shock Experienced by Expatriates in Oman and Omani Expatriates Abroad. Int. Journal of Business and Management, Vol 8, No. 13, pp 144-1

Naeem, A., Nadeem, A.B., Khan, U.I. (2015). Cultural shock and its effects on expatriates. Global Advance Research Journal of Management and Business Studies, Vol 4 (6), pp 248-258

Raco, J.R and Tanod, R.H.M. (2014). 'The phenomenological method in entrepreneurship, Int. J. Entrepreneurship and Small Business, Vol. 22, No. 3, pp 276-285

Shieh, C.J. (2014). Effects of culture shock and cross-cultural adaptation on learning satisfactioin of mainland China students studying in Taiwan. Revista Internacional de Socilogia Special Issue on Organizational Innovation, Vol. 72 (2), pp 57-67

Sinuany-Stern, Z., Israeli, Y., Bar-Eli, M. (2006). Application of analytical hierarchy process for the evaluation of basketball teams, Int. J. Sport Management and Marketing , Vol 1, No.3, pp. 193-207 